\title{
Effectiveness of human patient simulation education in improving infection control practices - A systematic review
}

\author{
Miia M Jansson ${ }^{1}$, Helvi A Kyngäs ${ }^{2,3}$, Maria S Kääriäinen² \\ 1. Division of Intensive Care, Department of Anesthesiology, Oulu University Hospital, Oulu, Finland. 2. Institute of Health \\ Science, University of Oulu, Oulu, Finland. 3. Medical Research Center Oulu, Oulu, Finland.
}

Correspondence: Miia M Jansson. Address: Division of Intensive Care, Department of Anesthesiology, Oulu University Hospital, Oulu, Finland. Email: miiajans@mail.student.oulu.fi

Received: September 3, 2013

DOI : $10.5430 /$ jnep.v4n4p12
Accepted: October 31, 2013

URL: http://dx.doi.org/10.5430/jnep.v4n4p12

\section{Abstract}

Background: Continuing education of healthcare personnel has been shown to play an essential role in infection control, associated with a sustained improvement in learning and clinical outcomes. However, the effectiveness of previous educational interventions in infection control is rather limited. Therefore, the aim of the study was to evaluate the effectiveness of human patient simulation (HPS) education in improving infection control practices on nursing continuing education.

Methods: A search strategy was conducted in eight multi-disciplinary databases and formulated in association with an information specialist (2003-2012). Two content and methodological experts selected the studies and assessed their quality independently. Only intervention studies, used alone or in conjunction with other educational interventions, were included in the review.

Results: Due to a lack of available studies, only one study was included in the final review. According to the results of that study, the use of patient biosimulator with a visual demonstration may have significant advantages in changing the behavior of healthcare personnel regarding infection control practices.

Conclusion: The effectiveness of HPS education in improving infection control practices on nursing continuing education is still uncertain due to the lack of published studies and robust evidence. There is a need for new, innovative educational intervention studies to educate, evaluate and improve knowledge, attitudes and performance regarding hand hygiene practices and invasive procedures.

\section{Key words}

Human patient simulation, Infection control, Continuing education, Nursing

\section{Introduction}

According to the European Centre for Disease Prevention and Control ${ }^{[1]}$, over four million patients are estimated to acquire a healthcare-associated infection (HAI) in the EU every year. In addition, the number of deaths occurring as a 
direct consequence of these infections is estimated to be at least $37,000{ }^{[2]}$. Approximately $20 \%-30 \%$ of HAIs are considered preventable through intensive hygiene and infection control programs.

Healthcare personnel adherence to infection control procedures is currently insufficient due to a lack of time, inaccessible supplies and lack of knowledge ${ }^{[3]}$. Continuing education of healthcare personnel has been shown to play an essential role in infection control ${ }^{[4-6]}$, associated with a sustained improvement in learning and clinical outcomes ${ }^{[4]}$. However, the effectiveness of previous educational interventions in infection control practices is rather limited.

Human patient simulation (HPS) education is an innovative and interactive teaching strategy used to replace or mimic real experiences with guided experiences that evoke or replicate substantial aspect of the real world ${ }^{[7,8]}$. In recent years, the effectiveness of HPS education in infection control practices has been investigated on medical education ${ }^{[9-11]}$. However, there is currently a lack of knowledge about the effectiveness of HPS education in improving infection control practices on nursing continuing education. Therefore, the aim of the present study was to evaluate the benefits of using HPS by performing a systematic review.

The main question addressed in the study was "What is the effectiveness of HPS education in improving infection control practices on nursing continuing education?" Only intervention studies, used alone or in conjunction with other educational interventions, were included in the review.

\section{Methods}

The reporting of the study complied with the PRISMA (Preferred Reporting Items for Systematic Reviews and Meta-Analyses) statement ${ }^{[12]}$.

\subsection{Search strategy}

The study was conducted in the fall of 2012 according to the Centre of Reviews and Dissemination's guidance for undertaking reviews in health care ${ }^{[13]}$. A preliminary search strategy was conducted in eight multidisciplinary databases (e.g., MEDLINE Ovid ${ }^{\circledR}$, CINAHL, Cochrane Library, Scopus, Web of Science, the Educational Resources Information Center, PsycINFO, Academic Search Premier) to identify optimal search terms and evaluate the effectiveness of HPS education in improving infection control practices on critical care nurses' continuing education ${ }^{[13,14]}$. Due to a lack of relevant research, the review was expanded to evaluate the effectiveness of HPS education in improving infection control practices of nurses in general.

The final review was conducted in eight multi-disciplinary databases (2003-2012) and formulated in association with an information specialist (see Table 1) ${ }^{[13,14]}$. Used search terms were: "simulat*" AND continuing OR graduate OR baccalaureate OR postgraduate OR ongoing OR clinical AND education AND nursing AND "cross infection*" OR "nosocomial infection*" OR "hai" OR "infection control". There was no language restriction.

Table 1. Databases and number of original studies

\begin{tabular}{ll}
\hline Database & Number of original studies \\
\hline MEDLINE Ovid & $(\mathbb{R}$ \\
CINAHL & 6 \\
Cochrane & 9 \\
Scopus & 6 \\
Web of Science & 1 \\
ERIC & 0 \\
PsycINFO & 0 \\
Academic Search Premier & 0 \\
\hline
\end{tabular}

Notes. $\mathrm{CINAHL}=$ Cumulative Index to Nursing and Allied Health Literature; ERIC $=$ Educational Resources Information Center.

Published by Sciedu Press 


\subsection{I nclusion criteria, study selection and quality assessment}

Inclusion criteria were tailored to the extremely specific research question, target population, interventions, outcomes and study design to guide decision-making (see Table 2$)^{[13]}$. The study selection process was conducted in two stages by the review team (e.g., content and methodological experts) to minimize bias and errors in the study selection process ${ }^{[13,15]}$. Firstly $(\mathrm{N}=22)$, duplicate publications $(n=10)$ within the eight different multidisciplinary databases were excluded from the review (see Table 1). Secondly, an initial screening of the titles $(n=12)$, abstracts $(n=5)$ and full texts $(n=3)$ were conducted against the predetermined inclusion criteria (see Figure 1$)^{[13,14]}$.

Table 2. Review questions and inclusion criteria

\begin{tabular}{ll}
\hline Review questions & Inclusion criteria \\
\hline Population & Registered nurses \\
Intervention & Human patient simulation education \\
& Continuing education, ongoing education, clinical education, postgraduate education \\
Outcomes & Learning outcomes: knowledge, skills, adherence \\
Study design & Clinical outcomes: hospital acquired infection, nosocomial infection, cross infection \\
\hline
\end{tabular}

Notes. RCT, Randomized controlled trial
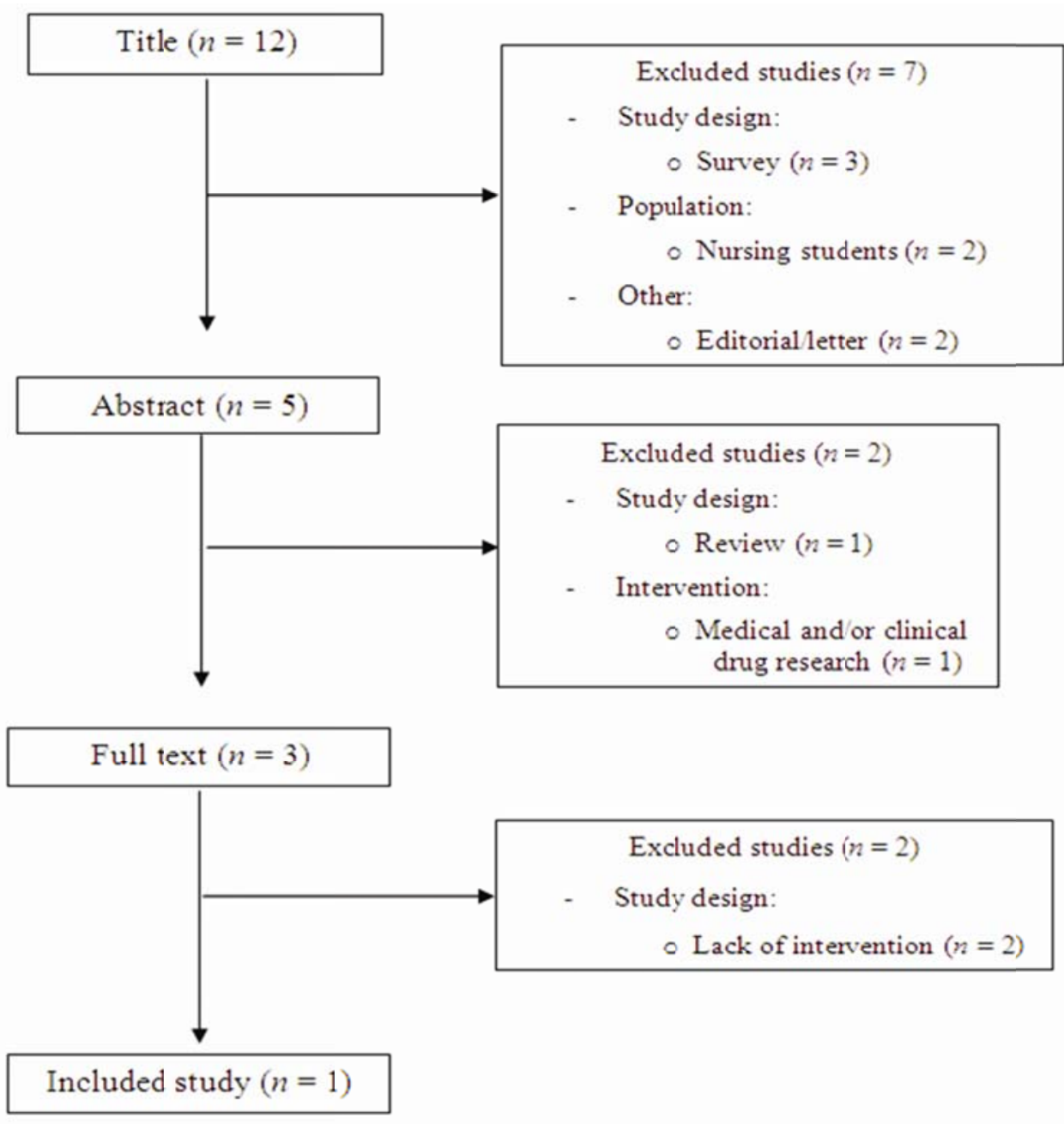

Figure 1. Flowchart of the study-selection process 
Finally, the widely used JBI Critical Appraisal Checklist for Randomised and Pseudo-Randomised Studies ${ }^{[14]}$ was used to assess the methodological quality of the relevant studies in order to avoid incorrect or misleading conclusions ${ }^{[13,14]}$. The quality of the studies was assessed by two by two content and methodological experts independently ${ }^{[13]}$, using a scoring system in which one point was awarded for the inclusion of each relevant criterion (quality score range, 0-10).

\subsection{Data extraction and synthesis}

The data extraction was tailored to the specific review question ${ }^{[13,14]}$ and objectives ${ }^{[14]}$ in order to obtain all the necessary information about the study characteristics (e.g., setting and participants, study designs, interventions, outcome measurements) and results of the included studies ${ }^{[13,14]}$. Moreover, the extracted data were cross-checked by both primary and secondary reviewers to minimize bias and errors in the data extraction process ${ }^{[13-15]}$. A two-tailed $P$ value less than .05 was considered statistically significant.

The principles of narrative synthesis were used to describe, evaluate, and summarize the findings of the included study ${ }^{[13]}$. The indexes of inter-rater reliability were not calculated ${ }^{[15]}$. However, there was complete agreement between the reviewers' final selection.

\section{Results}

Owing to the lack of available studies, only one study was included in the final review (see Table 3). The quality of the study by Carrico et al. ${ }^{[16]}$ was assessed as high (9 out of 10 points). One point was reduced due to lack of blinding.

Table 3. Study characteristics of included original study with quality scores $\geq 80 \%(n=1)$

\begin{tabular}{|c|c|c|c|c|c|}
\hline $\begin{array}{l}\text { Author, } \\
\text { Country }\end{array}$ & $\begin{array}{l}\text { Setting, } \\
\text { Participant }\end{array}$ & Design & Intervention & $\begin{array}{l}\text { Outcome } \\
\text { measurements }\end{array}$ & Results \\
\hline $\begin{array}{l}\text { Carrigo et } \\
\text { al., } 2007 \\
\text { USA }\end{array}$ & $\begin{array}{l}\text { University } \\
\text { hospital, } \\
\text { randomly } \\
\text { selected } \\
\text { emergency } \\
\text { department } \\
\text { registered } \\
\text { nurses }(n=20)\end{array}$ & $\begin{array}{l}\text { Quasi-experimental, } \\
\text { observational, } \\
\text { intervention study } \\
\text { with repeated } \\
\text { measurements }\end{array}$ & $\begin{array}{l}\text { The intervention } \\
\text { group received } \\
\text { supplemental } \\
\text { training using } \\
\text { biosimulator * with } \\
\text { visual } \\
\text { demonstration of } \\
\text { respiratory particle } \\
\text { dispersion, whereas } \\
\text { the control group } \\
\text { received classroom } \\
\text { training only. }\end{array}$ & $\begin{array}{l}\text { Knowledge was } \\
\text { assessed prior to the } \\
\text { classroom training. } \\
\text { Once classroom } \\
\text { training was } \\
\text { completed, } \\
\text { participants retook } \\
\text { the knowledge } \\
\text { assessments. } \\
\text { Following the } \\
\text { post-test, skills } \\
\text { were evaluated by } \\
\text { two trained } \\
\text { observers of nursing } \\
\text { practice. }\end{array}$ & $\begin{array}{l}\text { Nurses' knowledge was } \\
\text { improved significantly ( } p \\
=.007 \text { ) following } \\
\text { intervention, but the } \\
\text { difference between the } \\
\text { groups was not } \\
\text { statistically significant ( } p \\
=.24) \text {. } \\
\text { The intervention group's } \\
\text { skills to correctly use } \\
\text { personal protective } \\
\text { equipment increased } \\
\text { significantly ( } p=.04 \text { ) } \\
\text { compared to the control } \\
\text { group. }\end{array}$ \\
\hline
\end{tabular}

* Biosimulator, Medical Education Technologies, Inc. [METI], Sarasota, FL

The included paper described a single-center, quasi-experimental study with repeated measurements conducted in the USA among randomly allocated emergency department nurses $(n=20)$. The study demonstrated that the use of biosimulator (Medical Education Technologies, Inc. [METI], Sarasota, FL) with a visual training may have significant advantages in changing the behavior of healthcare personnel regarding infection control practices ${ }^{[16]}$.

A total of 114 observations were recorded: 56 for the control group and 58 for the intervention group. Participants who received supplemental visual training correctly utilized personal protective equipment statistically more often ( $74 \%$ vs. $53 \%, p=.04)$ than participants who received only standard classroom training ${ }^{[16]}$. 
However biosimulator with a visual training was not clearly a superior method compared to conventional standardized classroom training; participants' knowledge improved significantly $(p=.007)$ from 0.64 (SD 0.11) to 0.76 (SD 0.17) following intervention, but the difference between the control and intervention groups was not statistically significant $(p=$ $0.24)^{[16]}$.

\section{Discussion and conclusion}

\subsection{Discussion}

A comprehensive literature search strategy was formulated in association with an information specialist. The main findings were that the effectiveness of HPS education on nursing continuing education is still uncertain and nursing continuing education requires new and more effective evidence-based teaching methods to ensure patient safety and the quality of care.

However, the single included study provides new and important information about the effectiveness of the biosimulator with visual demonstration in changing the behavior of healthcare personnel regarding infection control practices ${ }^{[16]}$. In addition, the study identified significant transfer of learned skills to clinical practice.

The major limitations and potential sources of bias were related to the small sample size and lack of blinding, which limit the internal and external validity ${ }^{[15]}$. Nevertheless, despite the lack of clinical outcomes, the results of Carrigo et al. ${ }^{[16]}$ are in line with previous studies where the HPS education has been associated with significant improvements in medical practitioners' learning (e.g., knowledge, confidence, and skills) and clinical outcomes (e.g., arterial punctures, pneumothorax), which have been demonstrated by nonrandomized, two-group designs ${ }^{[12]}$. However, according to meta-analysis of peer-reviewed, published, controlled studies (1950-2010), HPS education does not seem to affect the incidence of catheter-associated bloodstream infections ${ }^{[12]}$.

The lack of significant findings regarding the level of knowledge in the included study is not surprising ${ }^{[16,17]}$, but contrasts with other studies of medical education ${ }^{[12,19]}$. HPS education allows participants to view the impact of disease transmission as opposed to simply hearing about it through traditional didactic education workers ${ }^{[16]}$. The components of the visual demonstration are based on the principles of adult workers ${ }^{[16]}$ and experimental learning, which are particularly suited for nurses' continuing education ${ }^{[20,21]}$, where integration of theory and practice is essential and ongoing ${ }^{[20]}$. Furthermore, simulations can be used to improve participants' technical knowledge ${ }^{[21]}$ and identify systemic problems that would otherwise be difficult to detect.

\subsection{Limitations}

The comprehensive search strategy was contained in eight multi-disciplinary databases and focused only on peer-reviewed empirical studies published during the last ten years (2003-2012), which may have led to publication bias ${ }^{[13]}$. In addition, the current body of literature is complicated by a lack of published studies and robust evidence. However, the quality of the original study was carefully assessed to ensure the validity of the review and to avoid incorrect or misleading conclusions ${ }^{[13-15]}$. In addition, the study selection process was documented (e.g., reference management program) and reported (e.g., flow chart of study selection process) in a way that enables it to be evaluated and reproduced ${ }^{[13,14]}$.

\subsection{Conclusions}

The effectiveness of HPS education in improving infection control practices on nursing continuing education is still questionable due to the lack of published studies and robust evidence. There is a need for new, innovative educational intervention studies to educate, evaluate and improve knowledge, attitudes and performance regarding hand hygiene 
practices and invasive procedures, such as catheterization and endotracheal suctioning, in order to understand, inform and develop current practices for the prevention of HAIs.

\section{Acknowledgements}

The authors wish to acknowledge the assistance of the information specialist Sirpa Grekula from the Oulu University Medical Library.

\section{References}

[1] European Centre for Disease Prevention and Control Report 2012. Reporting on 2010 surveillance data and 2011 epidemic intelligence data. ECDC, Stockholm, 2013.

[2] European Centre for Disease Prevention and Control. Surveillance of healthcare-associated infections in Europe, 2007. ECDC, Stockholm, 2012.

[3] Berhe M, Edmond M, Bearman G. Practices and an assessment of health care workers' perceptions of compliance with infection control knowledge of nosocomial infections. American Journal of Critical Care. 2005; 33: 55-57.

[4] Siegel JD, Rhinehart E, Jackson M, Chiarello L, and the Healthcare Infection Control Practices Advisory Committee. 2007 Guideline for Isolation Precautions: Preventing Transmission of Infectious Agents in Healthcare Settings. American Journal of Infection Control. 2007; 35: S65-64. PMid:18068815 http://dx.doi.org/10.1016/j.ajic.2007.10.007

[5] Masterton R.G, Galloway A, French G, et al. Guidelines for management of hospital-acquired pneumonia in the UK: Report of the Working Party on Hospital-Acquired Pneumonia of the British Society for Antimicrobial Chemotherapy. Journal of Antimicrobial Chemotherapy. 2008; 62: 5-34. PMid:18445577 http://dx.doi.org/10.1093/jac/dkn162

[6] Simerka P. Council Recommendation of 9 June 2009 on patient safety, including the prevention and control of healthcare associated infections. Official Journal of the European Union; 2009/C 151/1-6. http://dx.doi:10.3000/17252423.C_2009.151.eng.

[7] Lupien A.E. High-Fidelity Patient Simulation. In: Bradshaw MJ, Lowenstein AJ, Eds. Innovative teaching strategies in nursing and related health professions, fourth editions. Jones and Bartlett Publisher, Massachusetts, 2007.

[8] Gaba D.M. The future vision of simulation in health care. Quality \& Safety in Health Care. 2004; 13: i2-i10. PMid:15465951 http://dx.doi.org/10.1136/qshc.2004.009878

[9] Irene W.Y, Brindle M.E, Ronksley P.E, Lorenzetti D.L, Sauve R.S, Ghali W.A. Use of simulation-based education to improve outcomes of central venous catheterization: A systematic review and meta-analysis. Academic Medicine. 2011; 86: $1137-1147$. PMid:21785310 http://dx.doi.org/10.1097/ACM.0b013e318226a204

[10] Sekiguchi H, Tokita J.E, Minami T, Eisen L.A, Mayo P.H, Narasimhan M. A prerotational, simulation-based workshop improves the safety of central venous catheter insertion: results of a successful internal medicine house staff training program. CHEST. 2011; 140: 652-658. PMid:21659429 http://dx.doi.org/10.1378/chest.10-3319

[11] Latif RK, Bautista AF, Memon S.B, Smith E.A, Wang C, Wadhwa A, Carter M.B, Akca O. Teaching aseptic technique for central venous access under ultrasound guidance: A randomized trial comparing didactic training alone to didactic plus simulation-based training. Anesthesia and Analgesia. 2012; 114: 626-633. PMid:22190554 http://dx.doi.org/10.1213/ANE.0b013e3182405eb3

[12] Moher D, Liberati A, Tetzlaff J, Altman D. Preferred reporting items for systematic reviews and meta-analyses: The PRISMA statement. British Medical Journal. 2009; 339: 332-336. PMid:19622551

[13] Centre for Reviews and Dissemination (CRD). Systematic Reviews. CRD's guidance for undertaking reviews in health care. Centre for Reviews and Dissemination, University of York, 2009. http://dx.doi.org/10.1016/S1473-3099(10)70065-7

[14] Joanna Briggs Institute Reviewers' Manual 2011. Critical appraisal checklist for cohort/case control appraisal. Australia: The Joanna Briggs Institute, 2011.

[15] Polit D, Beck C. Nursing Research. Generating and Assessing Evidence for Nursing Practice. Eight Editions. Lippincott Williams \& Wilkins, Philadelphia, 2013.

[16] Carrigo R.M, Coty M.B, Goss L.K, Lajoie AS. Changing health care worker behavior in relation to respiratory disease transmission with a novel training approach that uses biosimulation. American Journal of Infection Control. 2007 ; 35: 14-19. PMid:17276786 http://dx.doi.org/10.1016/j.ajic.2005.12.013

[17] Dine C.J, Gersh R.E, Leary M, Riegel B.J, Bellini L.M, Abella B.S Improving cardiopulmonary resuscitation quality and resuscitation training by combining audiovisual feedback and debriefing. Criticical Care Medicine. 2008; 36: $2817-2822$. PMid:18766092 http://dx.doi.org/10.1097/CCM.0b013e318186fe37 
[18] Ford D.G, Seybert A.L, Smithburger P.L, Kubulinsky L.R, Samosky J.T, Kane-Gil S.L. Impact of simulation-based learning on medication error rates in critically ill patients. Intensive Care Medicine. 2010; 36: 1526-1531. PMid:20300731 http://dx.doi.org/10.1007/s00134-010-1860-2

[19] Pascual J.L, Holena D.N, Vella A, et al. Short simulation training improves objective skills in established advanced practioners managing emergencies on the ward and surgical intensive care unit. The Journal of TRAUMA Injury, Infection, and Critical Care. 2011; 71: 330-338. PMid:21825935 http://dx.doi.org/10.1097/TA.0b013e31821f4721

[20] Fanning R.M, Gaba D.G. The role of debriefing in simulation-based learning. Simulation in Healthcare. $2007 ; 2$ : $115-125$. PMid:19088616 http://dx.doi.org/10.1097/SIH.0b013e3180315539

[21] Grainger C, Griswold A. Critical thinking in nursing education. In: Bradshaw MJ, Lowenstein AJ, Eds. Innovative teaching strategies in nursing and related health professions, fourth editions. Jones and Bartlett Publisher, Massachusetts, 2007. 